\title{
Application of soft computing models in streamflow forecasting
}

Rana Muhammad Adnan MEng, PhD

Assistant Professor, Faculty of Agricultural and Biosystems Engineering and Technology, Muhammad Nawaz Sharif University of Agriculture, Multan, Pakistan

\section{Xiaohui Yuan PhD}

Professor, School of Hydropower and Information Engineering, Huazhong University of Science and Technology, Wuhan, China (corresponding author: yxh71@163.com) (Orcid:0000-0002-0939-2704)

\section{Ozgur Kisi PhD}

Professor, Faculty of Natural Sciences and Engineering, Ilia State University, Tbilisi, Georgia
Yanbin Yuan PhD

Professor, School of Resource and Environmental Engineering, Wuhan University of Technology, Wuhan, China

Muhammad Tayyab MEng, PhD

Assistant Professor, College of Hydraulic \& Environmental Engineering, China Three Gorges University, Yichang, China

Xiaohui Lei PhD

Professor, State Key Laboratory of Simulation and Regulation of Water Cycle in River Basin, China Institute of Water Resources and Hydropower Research, Beijing, China (corresponding author: leixiaohui_sky@163.com)

The accuracy of five soft computing techniques was assessed for the prediction of monthly streamflow of the Gilgit river basin by a cross-validation method. The five techniques assessed were the feed-forward neural network (FFNN), the radial basis neural network (RBNN), the generalised regression neural network (GRNN), the adaptive neuro fuzzy inference system with grid partition (Anfis-GP) and the adaptive neuro fuzzy inference system with subtractive clustering (Anfis-SC). The interaction between temperature and streamflow was considered in the study. Two statistical indexes, mean square error (MSE) and coefficient of determination $\left(R^{2}\right)$, were used to evaluate the performances of the models. In all applications, RBNN and Anfis-SC were found to give more accurate results than the FFNN, GRNN and Anfis-GP models. The effect of periodicity was also examined by adding a periodicity component into the applied models and the results were compared with a statistical model (seasonal autoregressive integrated moving average (Sarima)) to check the prediction accuracy. The results of this comparison showed that periodicity inputs improved the prediction accuracy of the applied models and, in all cases, the soft computing models performed much better than the Sarima model. The periodic RBNN and Anfis-SC models increased the MSE accuracy of Sarima by $25 \cdot 5-24 \cdot 7 \%$.

\section{Notation}

\section{$A_{i}, B_{i}, C_{i}$}

$\left\{a_{i}, b_{i}, c_{i}\right)$

$B$

$D$

$d$

$e_{t}$

$L$

$N$

$O_{i j}$

$\left\{p_{i}, q_{i}, r_{i}, z_{i}\right\}$

$S_{\mathrm{f}}$

$\bar{S}_{\mathrm{f}}$

$S_{i}$

$S_{\max }$

$S_{\min }$

$S_{\mathrm{n}}$

$S_{\mathrm{o}}$

$\bar{S}_{\mathrm{O}}$

$S_{t}$

$T_{i}$

$T_{\max }$

$T_{\min }$

$T_{\mathrm{n}}$

$W_{i}$

$\boldsymbol{X}$ fuzzy sets associated with node $i$

parameter set of the shape function

lag operator

seasonal difference

non-seasonal difference

independent identically distributed process

seasonality lag

total number of observations

output of the $i$ th node in unit $j$

parameter set of output layer

forecasted streamflow

average of forecasted streamflow

actual streamflow

maximum value of streamflow

minimum value of streamflow

normalised streamflow

observed streamflow

average of observed streamflow

streamflow at time $t$

actual streamflow

maximum temperature

minimum temperature

normalised temperature

weight vector

input vector

$X_{1}, X_{2}, X_{3}$
$\theta_{\mathrm{NMA}}$
$\theta_{\mathrm{SMA}}$
$\mu_{A_{i}}(\boldsymbol{X})$
$\sigma^{2}$
$\Phi_{\mathrm{NAR}}$
$\Phi_{\mathrm{SAR}}$

inputs to node $i$

non-seasonal moving average parameter seasonal moving average parameter membership function of node $i$ normalisation factor non-seasonal autoregressive parameter seasonal autoregressive parameter

\section{Introduction}

Prediction of streamflow is a key step in the planning of water projects, irrigation systems and hydropower systems and optimising the use of water resources. The identification of suitable models for predicting monthly streamflows is very important for the effective utilisation of water. Many models have been developed for streamflow prediction. These models can be broadly divided into two categories, linear models and nonlinear models. In linear models, a linear relationship is assumed among the variables of hydrological time series. In the linear models category, the autoregressive integrated moving average (Arima) model is the most famous (Chen et al., 2014) and has been extensively used for hydrological time series analysis. Arima models predict the time series on the basis of classical Box and Jenkins methodology (Bartholomew, 1971). Many researchers have used Arima models to predict streamflow (Modarres and Ouarda, 2013; Valipour, 2015). The streamflow prediction relies on many 
factors such as evapotranspiration, temperature, precipitation, snow pack and so on. These factors make the streamflow process non-linear in nature. These linear models perform well when the data only depend on previous observations, but they perform poorly when the data also depend on other exogenous variables. In the last decade, non-linear models such as artificial neural networks (Anns) and the adaptive neuro fuzzy inference system (Anfis) have demonstrated good results in predicting the non-linear behaviour of streamflows (Emamgholizadeh et al., 2014).

Anns have been extensively applied in the study of streamflow prediction. Cigizoglu and Kisi (2005) used a generalised regression neural network (GRNN) and a feed-forward neural network (FFNN) to predict streamflows. The results of that study indicated that the GRNN performed better than the FFNN. Hu et al. (2005) analysed seven different watersheds in China using an Ann model, with streamflows, precipitation and degree of watershed wetness used as inputs for the model. The results of their study showed that the multi-layer FFNN performed better than a back-propagation neural network in six of the seven watersheds. Kisi (2007) used FFNN, GRNN and radial basis neural network (RBNN) models to predict the streamflows of the Filyos River and Ergene River. In this study, the training data were divided into seven sub-sets and different neural network algorithms were applied. The results of the study showed that the Levenberg-Marquardt algorithm performed better than other Ann algorithms in daily streamflow forecasting. Mutlu et al. (2008) used RBNN and FFNN models for daily streamflow prediction at multiple sites of the Eucha watershed and the results showed that Anns could be successfully applied to multiple sites. Using an RBNN model to predict short-term streamflow in some catchments of Africa, Kagoda et al. (2010) showed that the RBNN performed better in catchments having short-length training data. Mehr et al. (2015) investigated the prediction of monthly streamflows of the Coruh River in Turkey with RBNN, GRNN and FFNN methods. The RBNN was found to give better performance than the other two neural network models.

The Anfis model has received much attention by researchers due to its flexible nature. This model can capture the nonlinear behaviour of hydrological time series. Anfis has also been extensively used in different areas of water resource studies in the last decade (Cobaner, 2011; Chu and Chang, 2009; Talebizadeh and Moridnejad, 2011). El-Shafie et al. (2007) used Anfis to predict monthly inflow to the Aswan high dam on the Nile. They compared the results of the Anfis model with those of an Ann model and showed that Anfis performed better at that site. Pramanik and Panda (2009) investigated the streamflows of Mahanadi River in India using Anfis and Ann models, and the Anfis model was also found to offer better performance at that site. Sanikhani and Kisi (2012) applied two Anfis models - Anfis with grid partition (Anfis-GP) and Anfis with subtractive clustering (Anfis-SC) - to study the monthly flow data of Garzan stream in Turkey; they also used these two models to estimate the streamflows of a nearby river station. Greco (2012) used Anfis to predict the daily streamflow of Volturno River in Italy. In that study, daily streamflows and daily rainfall heights were used as input variables. Sharma et al. (2015) applied the Anfis model to investigate a watershed affected by the El Niño southern oscillation (ENSO) in southern USA. The results of that study showed that Anfis could be successfully applied to ENSO-affected watershed areas to predict streamflow. Talei et al. (2010) applied an Anfis-GP model to analyse rainfallrunoff process. For this research, data were collected from an experimental setup equipped with measuring devices. Kisi (2015) applied Anfis to predict streamflow and also used a fuzzy model to estimate the discharges of a nearby station.

The study reported in this paper investigated the applicability of FFNN, GRNN, RBNN, Anfis-GP, Anfis-SC and seasonal autoregressive integrated moving average (Sarima) models to predict monthly streamflows of the Gilgit river basin. Antecedent streamflows and temperature values were taken as input variables. To the best knowledge of the authors, there is no published work in the literature that predicts streamflows by comparing FFNN, GRNN, RBNN, Anfis-SC, Anfis-GP and Sarima models and also using temperature data as inputs.

The paper is organised as follows. In Section 2, the basic structure of the FFNN, GRNN, RBNN, Anfis-GP, Anfis-SC and Sarima models is described and the methodology used to build these models is explained. Section 3 describes the location of the study area, the data collection source and data distribution. In Section 4, three neural network techniques, two fuzzy techniques and one statistical model are applied to the monthly streamflow data for forecasting one-month-ahead streamflows. Conclusions are presented in Section 5.

\section{Models applied}

\section{$2.1 \quad$ FFNNs}

The FFNN is probably the most popular neural network used for the prediction of different hydrology variables (Maier and Dandy, 2000). The FFNN architecture basically consists of three layers - an input layer, a hidden layer and an output layer, as shown in Figure 1. The number of inputs decides the number of nodes in the first layer. The hidden layer consists of hidden units that provide non-linearities for the network. Data are passed from one layer to another layer with connected weights, which determine the strength of the connections. Initialisation of these weights is determined through a random fashion and, after completing the training process, the connection weights should be fixed. The primary objective of the FFNN is to minimise the estimation error and produce output values closer to targets. Nourani et al. (2013) give a detailed description of the FFNN. 


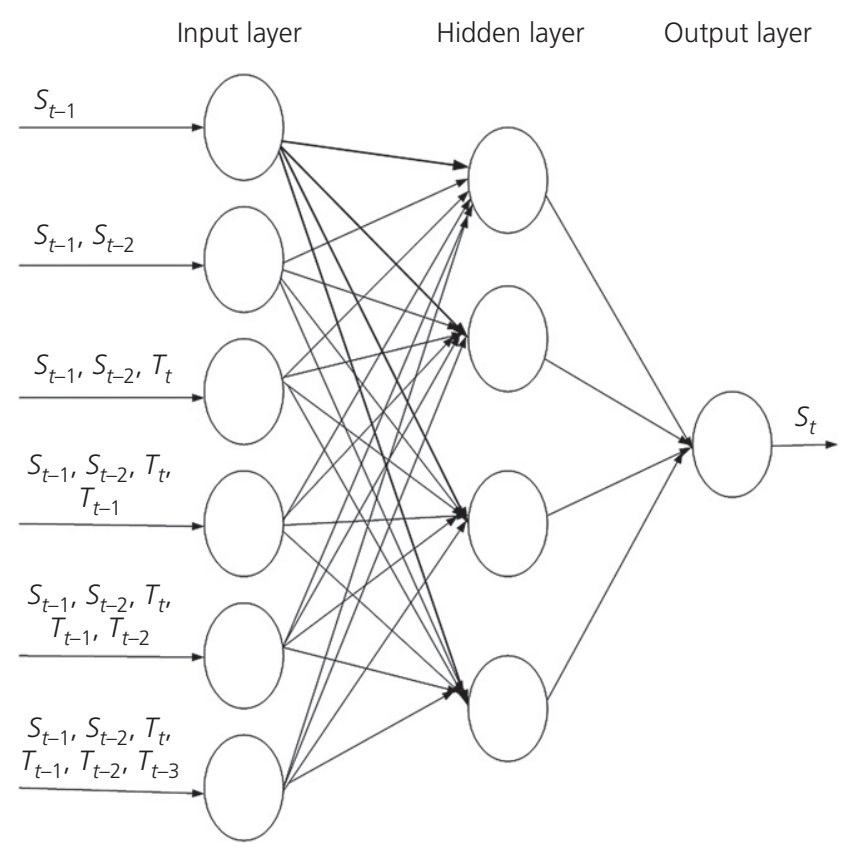

Figure 1. FFNN model for streamflow forecasting

\subsection{RBNNs}

In RBNNs, a radial basis function is used as a replacement for the sigmoidal transfer function. Many researchers have used RBNNs for environmental studies (Azmathullah et al., 2005; Tahershamsi et al., 2012). In the RBNN, the input layer is composed of signal nodes and the hidden layer consists of basis functions. The number of basis functions should be less than the number of data points in the input dataset. The basic architecture of the RBNN is shown in Figure 2. Among several radial basis functions, the Gaussian basis function is most often used. In the case of application of a Gaussian function, the activation level $O_{i j}$ of hidden unit $j$ is calculated using

1. $O_{i j}=\exp \left(\frac{-\left(\boldsymbol{X}-\boldsymbol{W}_{i}\right) \times\left(\boldsymbol{X}-\boldsymbol{W}_{i}\right)}{2 \sigma_{j}^{2}}\right)+0 \cdot 2$

where $\boldsymbol{X}$ is the input vector, $\boldsymbol{W}_{i}$ is the weight vector and $\sigma^{2}$ is the normalisation factor.

\subsection{GRNNs}

GRNNs were introduced by Specht (1991). GRNNs only use training data with the back-propagation method to derive the estimation function. In contrast to FFNN and RBNN models, the GRNN consists of four layers - an input layer, a (hidden) pattern layer, a summation layer and an output layer. The basic architecture of the GRNN is shown in Figure 3. The first layer consists of input units and the second layer transfers outputs to the summation layer. The summation layer consists of two neurons - the S-summation neuron and the D-summation neuron. The sum of the weighted outputs of the

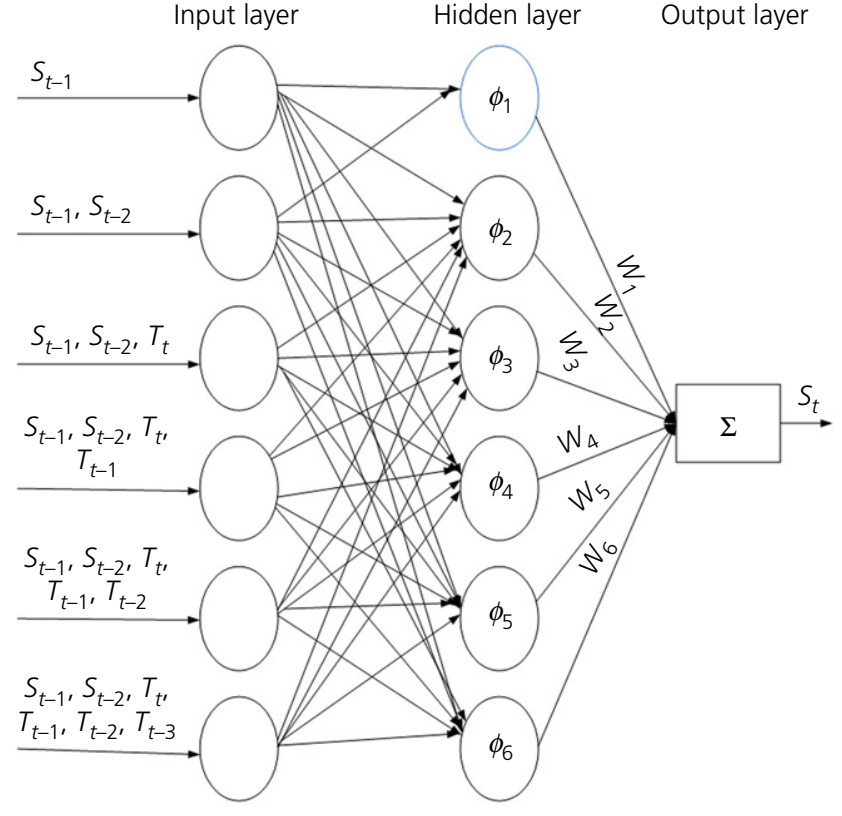

Figure 2. RBNN model for streamflow forecasting

pattern layer is computed by the S-summation neuron whereas the sum of unweighted outputs of the pattern layer is calculated by the D-summation neuron. Finally, the fourth layer consists of the output units.

\subsection{Anfis}

Anfis is a novel architecture that combines neural networks and fuzzy inference systems. Anfis has the capability of approximating any real continuous function on a compact set to any degree of accuracy. Anfis uses a neural network learning algorithm to construct a set of fuzzy if-then rules with appropriate membership functions (MFs) from the stipulated input-output pairs. Many types of inference systems have been reported in the literature (Takagi and Sugeno, 1985). Takagi and Sugeno's fuzzy structure of the Anfis model is computationally efficient and has mathematical intractable defuzzification operations. It is the most popular candidate for fuzzy modelling. It consists of five layers, as shown in Figure 4.

In layer 1, each node generates a membership grade of a linguistic model. The membership grades for each input in the corresponding fuzzy sets are estimated as

2. $O_{i, 1}=\mu_{A_{i}}\left(X_{1}\right) \quad$ for $i=1,2$

3. $O_{i, 1}=\mu_{B_{i-2}}\left(X_{2}\right)$ for $i=3,4$

4. $O_{i, 1}=\mu_{C_{i-4}}\left(X_{3}\right) \quad$ for $i=5,6$ 


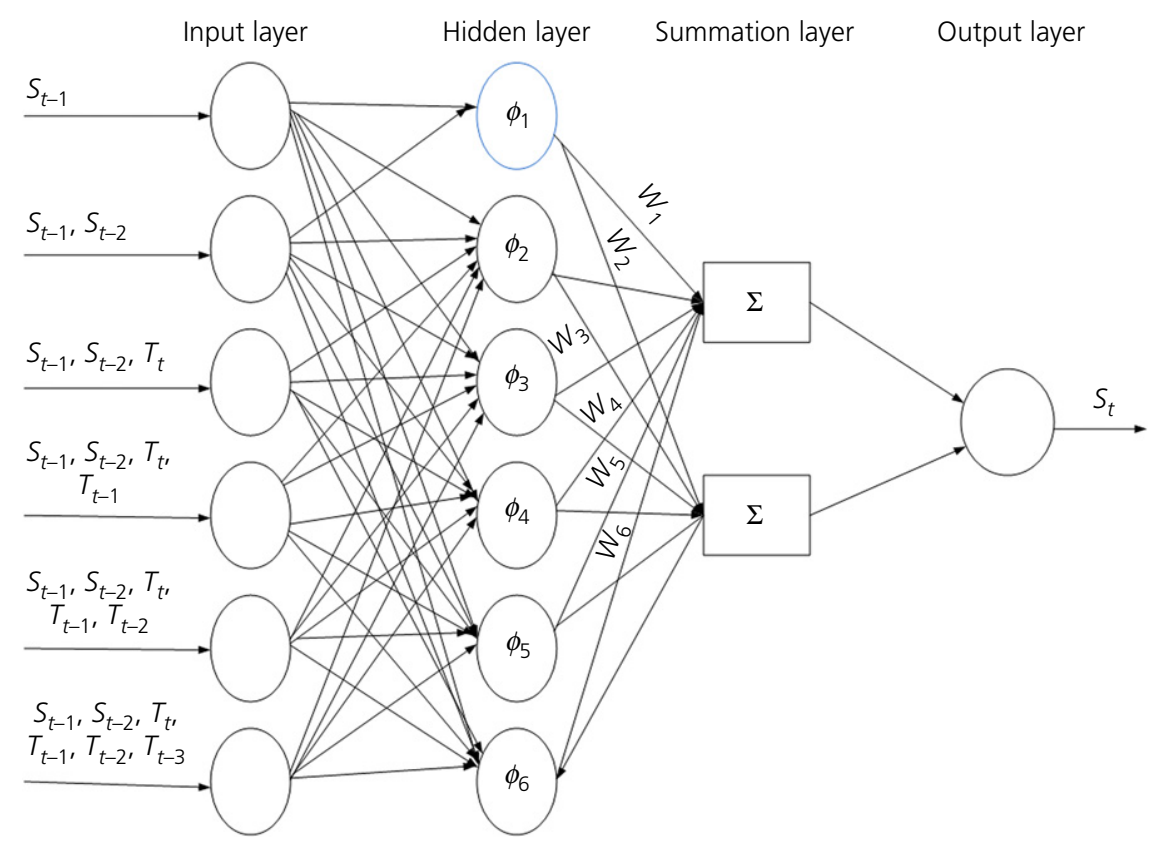

Figure 3. GRNN model for streamflow forecasting

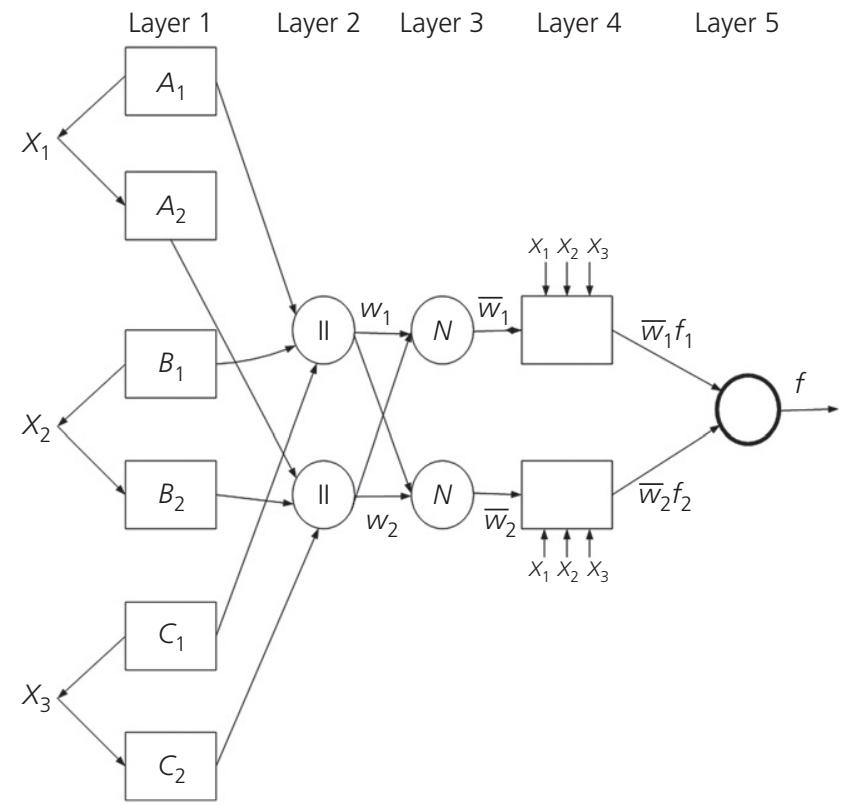

Figure 4. Schematic diagram of Anfis model

where $X_{1}, X_{2}$ and $X_{3}$ are inputs to node $i$ and $A_{i}, B_{i}$ and $C_{i}$ are the fuzzy sets associated with this node, identified by the shape of the MF. The MFs for $A$ and $B$ are generally described by a generalised bell function, for example

5. $\mu_{A_{i}}(\boldsymbol{X})=\frac{1}{1+\left[\left(\boldsymbol{X}-c_{i}\right) / a_{i}\right]^{2 b_{i}}}$ where $\left\{a_{i}, b_{i}, c_{i}\right)$ is the parameter set that changes the shape of the bell-shaped function with a maximum equal to 1 and minimum equal to 0 .

In layer 2, the nodes are labelled as II, which multiply the incoming signal and the output product

6. $O_{i, 2}=w_{i}=\mu_{A_{i}}\left(\boldsymbol{X}_{1}\right) \cdot \mu_{B_{i}}\left(\boldsymbol{X}_{2}\right) \cdot \mu_{C_{i}}\left(\boldsymbol{X}_{3}\right), \quad i=1,2$

In layer 3, every node of the layer calculates the relation between the $i$ th rule firing strength to the sum of all rules' firing strengths, labelled as $N$

7. $O_{i, 3}=\bar{w}_{i}=\frac{w_{1}}{w_{1}+w_{2}}, \quad i=1,2$

Layer 4 computes the sum of signals of third and second layer of the network

8. $O_{i, 4}=\bar{w}_{i} f_{i}=\bar{w}_{i}\left(p_{i} \boldsymbol{X}_{1}+q_{i} \boldsymbol{X}_{2}+r_{i} \boldsymbol{X}_{3}+z_{i}\right)$

where $\bar{w}_{i}$ is the output of layer 3 and $\left\{p_{i}, q_{i}, r_{i}, z_{i}\right\}$ is the parameter set.

Layer 5 comprises a single node, which calculates the overall output of Anfis and is labelled as $\Sigma$.

9. $O_{i, 5}=\sum_{i} \bar{w}_{i} f_{i}=\frac{\sum_{i} w_{i} f_{i}}{\sum_{i} w_{i}}$ 
The Anfis-GP model is obtained by combining Anfis and grid partition. Grid partition uses axis-paralleled partition based on a predefined number of MFs to divide the input space into rectangular subspaces. In Anfis-GP, by increasing the number of input variables, the number of fuzzy rules will increase exponentially. For instance, if there are $n$ input variables and $m$ MFs, then the total number of fuzzy rules will be $m^{n}$. More details about Anfis-GP can be found elsewhere (Abonyi et al., 1999).

Anfis-SC is an extension of the mountain clustering approach suggested by Yager and Filev (1994), which combines the Anfis model with the subtractive clustering technique. The advantage of this method is that it eliminates the need to specify a grid resolution in order to reduce the computational complexity of the former mountain clustering method. Chiu (1994) proposed a modified method. In this method, each data point is considered as a potential cluster centre and the potential of this data point is measured by its distance to all other points. A data point that has many neighbouring data points will have a high potential value. The influential radius should be identified to determine the number of clusters. Selection of a small radius produces many clusters and also requires more rules. Therefore, selection of suitable radii is important for clustering of the data space. The detailed procedure of Anfis-SC is described by Cobaner (2011).

\subsection{Sarima}

The seasonal Arima model, Sarima, is used to deal with seasonality. The Sarima model can be explained as Arima $(p, d, q)(P, D, Q)_{L}$, where $p$ represents the non-seasonal autoregressive term, $q$ represents the non-seasonal moving average term, $d$ represents the non-seasonal differencing terms and $(P, D, Q)_{L}$ represents the seasonal autoregressive, seasonal moving average and seasonal difference terms, respectively. The general form of Sarima $(p, d, q)(P, D, Q)_{L}$ model can be written as follows by using the backshift operator

10.

$$
\begin{gathered}
\Phi_{\mathrm{NAR}}(B) \Phi_{\mathrm{SAR}}\left(B^{L}\right)(1-B)^{d}\left(1-B^{L}\right)^{D} S_{t}= \\
\theta_{\mathrm{NMA}}(B) \theta_{\mathrm{SMA}}\left(B^{L}\right) e_{\mathrm{t}}
\end{gathered}
$$

where $L$ is the seasonality lag, $\Phi_{\mathrm{NAR}}$ is a non-seasonal autoregressive parameter, $\Phi_{\mathrm{SAR}}$ is a seasonal autoregressive parameter, $\theta_{\mathrm{NMA}}$ is a non-seasonal moving average parameter, $\theta_{\text {SMA }}$ is a seasonal moving average parameter, $D$ is the seasonal difference, $B$ is the lag operator, $d$ is the non-seasonal difference and $S_{t}$ is the streamflow at time $t$. The stepwise procedure of the Sarima model to predict streamflow is shown in Figure 5.

\section{Data collection and data preprocessing}

\subsection{Study area}

Monthly streamflow data from the Gilgit river basin, situated in the Koh-Hindu Kush region of Pakistan, were used in this study. The drainage area of this site is $12660 \mathrm{~km}^{2}$ and the

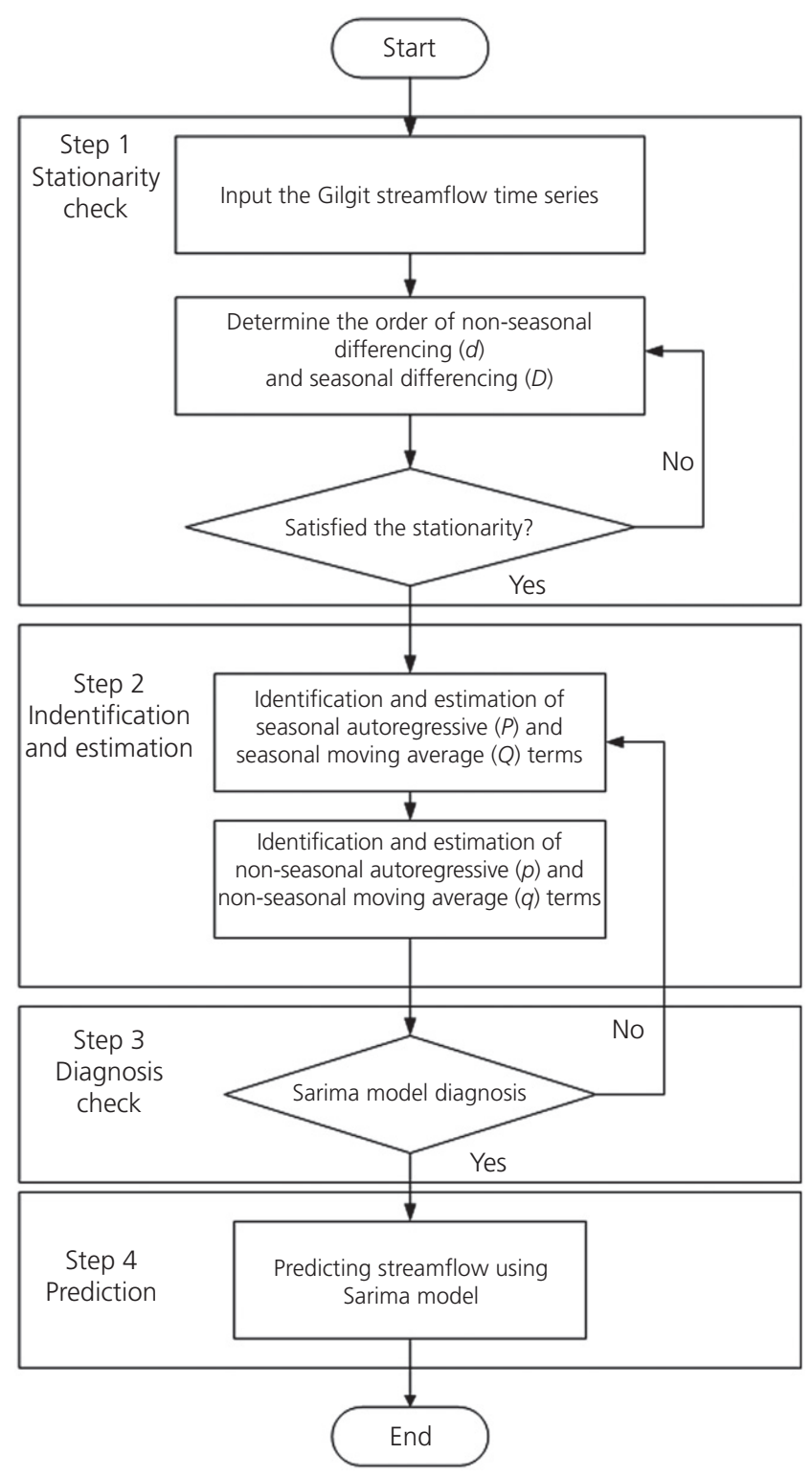

Figure 5. Block diagram of Sarima model for streamflow forecasting

catchment elevation is $3997 \mathrm{~m}$. Figure 6 shows the location of the study site. The Pakistan Water and Power Development Authority (WAPDA) has installed one flow gauging station (Gilgit hydrometric station) in this area for flow recording and one meteorological station (Gilgit meteorological station) for temperature and precipitation recording. Recorded monthly streamflow and temperature data from these stations were obtained, through WAPDA, for the period 1963-2010. According to the 1963-2010 WAPDA data, covering a period of 48 years, the mean annual flow of the river is $283 \mathrm{~m}^{3} / \mathrm{s}$ and the mean annual temperature is $15 \cdot 8^{\circ} \mathrm{C}$.

A cross-validation method was adopted in this study. Using this method, the whole dataset was divided into $k$ parts; then, 


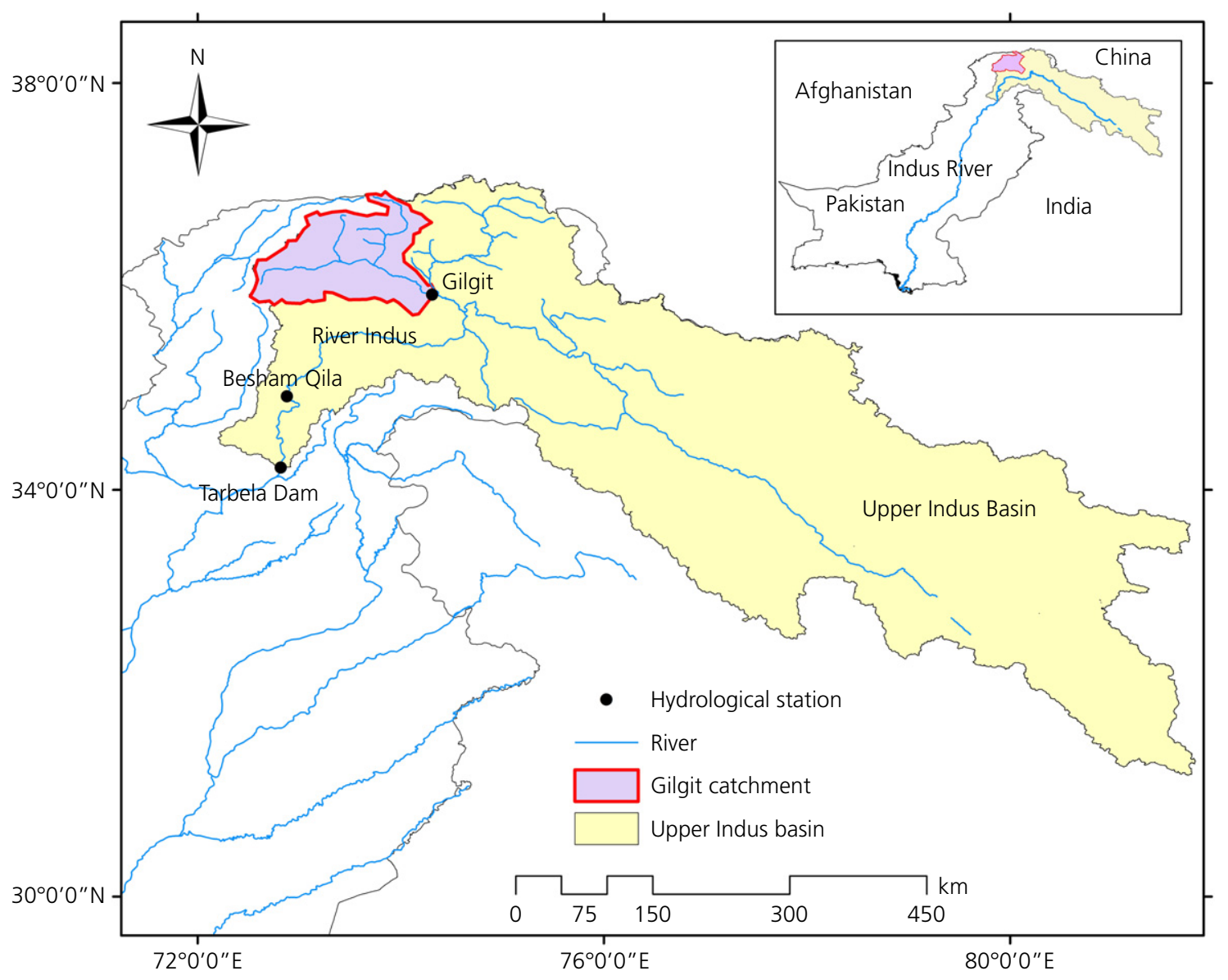

Figure 6. Study area including Gilgit hydrometric and Gilgit meteorological stations, Pakistan

$k-1$ parts were used to train the model and the remainder were used to test the accuracy of the model. This process was repeated $k$ times till every part of the data was used for testing. In addition, the whole dataset was divided into four equal parts. In all the applications, three parts were used to train and one part was used to test the model. This procedure was repeated four times until every part of the data was used to test the model. The monthly streamflow and temperature time series statistics are given in Table 1. In Table 1, WD represents the whole dataset whereas M1, M2, M3 and M4 represent four equal parts of the whole dataset for cross-validation analysis. The observed streamflow and temperature data show high positive skewness. In addition, the auto-correlations for both time series show very weak persistence.

\subsection{Performance criteria and data normalisation}

Two statistical indices were used to compare the performances of the FFNN, GRNN, RBNN, Anfis-GP and Anfis-SC models - the mean square error (MSE) and the determination coefficient $\left(R^{2}\right)$. The MSE is a generally used statistical index for measuring error in a prediction with respect to observed data while $R^{2}$ explains the degree of collinearity between predicted and original data. These indexes are widely used in the field of hydrology for evaluating model performance. In this study, the MSE and $R^{2}$ were calculated using

11. $\mathrm{MSE}=\frac{1}{N} \sum\left(S_{\mathrm{o}}-S_{\mathrm{f}}\right)^{2}$

12. $R^{2}=\frac{\sum\left(S_{\mathrm{o}}-\bar{S}_{\mathrm{o}}\right)\left(S_{\mathrm{f}}-\bar{S}_{\mathrm{f}}\right)}{\sqrt{\sum\left(S_{\mathrm{o}}-\bar{S}_{\mathrm{o}}\right) \sum\left(S_{\mathrm{f}}-\bar{S}_{\mathrm{f}}\right)^{2}}}$

where $N$ is the total number of observations, $S_{\mathrm{o}}$ is the observed flow, $S_{\mathrm{f}}$ is the forecasted streamflow, $\bar{S}_{\mathrm{o}}$ is the average streamflow and $\bar{S}_{\mathrm{f}}$ is the average forecasted flow.

Before applying the data to the models, the numbers of inputs were selected to predict the streamflow. For this purpose, crosscorrelation and partial auto-correlation analyses were applied to the streamflow and temperature time series to determine the effect of preceding streamflow and temperature values. According to Figure 7 , the partial auto-correlation function 
Table 1. Monthly statistics of streamflow and temperature datasets

\begin{tabular}{|c|c|c|c|c|c|c|c|c|}
\hline Data & Min. & Max. & Mean & Standard deviation & Skewness & $\operatorname{Lag} 1$ & $\operatorname{Lag} 2$ & $\operatorname{Lag} 3$ \\
\hline \multicolumn{9}{|c|}{ Dataset WD (1963-2010) } \\
\hline Streamflow: $\mathrm{m}^{3} \mathrm{~s}^{-1}$ & $35 \cdot 3$ & 1400 & $290 \cdot 9$ & $318 \cdot 4$ & $1 \cdot 31$ & 0.709 & 0.208 & -0.199 \\
\hline Temperature: ${ }^{\circ} \mathrm{C}$ & $1 \cdot 1$ & $30 \cdot 7$ & $15 \cdot 8$ & $8 \cdot 2$ & -0.08 & 0.846 & 0.476 & -0.012 \\
\hline \multicolumn{9}{|c|}{ Dataset M1 (1999-2010) } \\
\hline Streamflow: $\mathrm{m}^{3} \mathrm{~s}^{-1}$ & $35 \cdot 3$ & 1400 & $305 \cdot 7$ & $323 \cdot 3$ & $1 \cdot 4$ & 0.718 & 0.236 & -0.177 \\
\hline Temperature: ${ }^{\circ} \mathrm{C}$ & $2 \cdot 4$ & $27 \cdot 9$ & $16 \cdot 0$ & $7 \cdot 8$ & $-0 \cdot 2$ & 0.841 & 0.467 & -0.022 \\
\hline \multicolumn{9}{|c|}{ Dataset M2 (1987-1998) } \\
\hline Streamflow: $\mathrm{m}^{3} \mathrm{~s}^{-1}$ & $39 \cdot 9$ & 1339 & $289 \cdot 3$ & $316 \cdot 3$ & $1 \cdot 3$ & 0.715 & $0 \cdot 200$ & -0.215 \\
\hline Temperature: ${ }^{\circ} \mathrm{C}$ & $1 \cdot 1$ & $29 \cdot 0$ & $15 \cdot 6$ & $8 \cdot 1$ & $-0 \cdot 1$ & 0.845 & 0.470 & -0.017 \\
\hline \multicolumn{9}{|c|}{ Dataset M3 (1975-1986) } \\
\hline Streamflow: $\mathrm{m}^{3} \mathrm{~s}^{-1}$ & $38 \cdot 7$ & 1276 & $281 \cdot 4$ & $321 \cdot 3$ & $1 \cdot 4$ & 0.689 & 0.178 & -0.217 \\
\hline Temperature: ${ }^{\circ} \mathrm{C}$ & $2 \cdot 3$ & $30 \cdot 7$ & $15 \cdot 8$ & $8 \cdot 5$ & $-0 \cdot 1$ & 0.843 & 0.469 & -0.018 \\
\hline \multicolumn{9}{|c|}{ Dataset M4 (1963-1974) } \\
\hline Streamflow: $\mathrm{m}^{3} \mathrm{~s}^{-1}$ & $41 \cdot 7$ & 1156 & $287 \cdot 1$ & $315 \cdot 6$ & $1 \cdot 20$ & 0.703 & 0.188 & -0.226 \\
\hline Temperature: ${ }^{\circ} \mathrm{C}$ & $2 \cdot 0$ & 29 & $15 \cdot 6$ & $8 \cdot 5$ & -0.06 & 0.845 & 0.465 & -0.026 \\
\hline
\end{tabular}

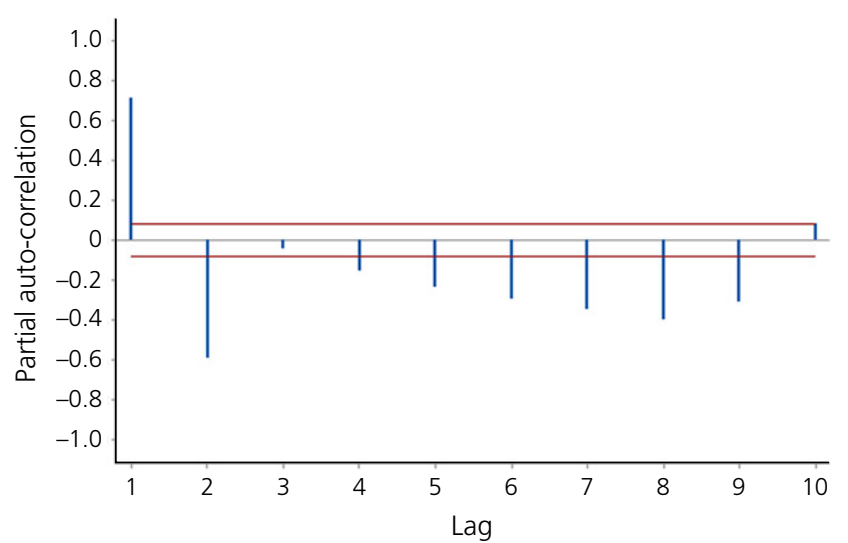

(a)

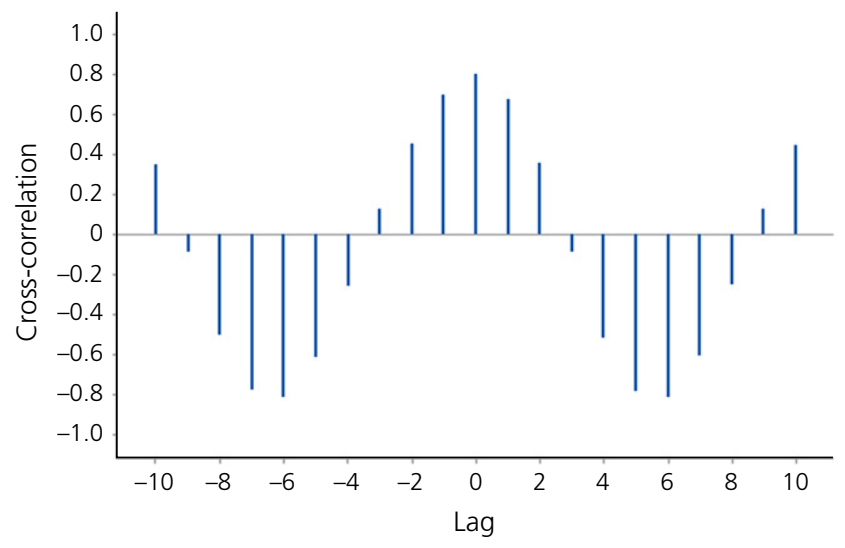

(b)

Figure 7. (a) Partial autocorrelation function of streamflow. (b) Cross-correlation function of streamflow and temperature time series

of the streamflow series showed significant correlation up to lag 2, whereas the cross-correlation function for the plot of the temperature time series indicated significant correlation up to lag 4 . In the present study, the six following input combinations were selected to predict streamflow at time $t\left(S_{t}\right)$
(I) $S_{t-1}$
(II) $S_{t-1}, S_{t-2}$
(III) $S_{t-1}, S_{t-2}, T_{t}$
(IV) $S_{t-1}, S_{t-2}, T_{t}, T_{t-1}$
(V) $S_{t-1}, S_{t-2}, T_{t}, T_{t-1}, T_{t-2}$
(VI) $S_{t-1}, S_{t-2}, T_{t}, T_{t-1}, T_{t-2}, T_{t-3}$.

Five different program codes, including neural networks and fuzzy logic toolboxes, were written in Matlab language for the FFNN, RBNN, GRNN, Anfis-GP and Anfis-SC simulations. The input and output values were normalised before training the network to improve the efficiency of all the models by using Equations 13 and 14

13. $S_{\mathrm{n}}=0 \cdot 6\left(\frac{S_{i}-S_{\min }}{S_{\max }-S_{\min }}\right)+0 \cdot 2$

14. $T_{\mathrm{n}}=0 \cdot 6\left(\frac{T_{i}-T_{\min }}{T_{\max }-T_{\min }}\right)+0 \cdot 2$

Here, $S_{\min }, S_{\max }$ and $T_{\min }, T_{\max }$ denote the minimum and maximum values of the streamflow and temperature time series, respectively, and $S_{i}, S_{\mathrm{n}}, T_{i}$ and $T_{\mathrm{n}}$ represent exhibit the actual streamflow, normalised streamflow, actual temperature and normalised temperature, respectively. In this study, the streamflow and temperature data were normalised in the range of 0.2 and $0 \cdot 8$ to increase the prediction flexibility.

\section{Results and discussion}

\subsection{FFNN, GRNN, RBNN, Anfis-SC, Anfis-GP applications}

For the FFNN applications, the network architecture consists of the input layer, which has one to six inputs for the input 
combinations I to VI listed in Section 3.2, respectively, and one output layer. The number of neurons in the hidden layer is difficult to determine because no specific methodology is available. Thus, the optimal numbers of hidden-layer neurons were determined through a trial-and-error procedure. In each trial, the sum of MSEs was used as a criterion for selecting the optimal number of hidden-layer neurons. For each input combination, training of the FFNN was started with two hidden neurons. This was then increased, one by one, up to 20 hidden neurons to determine the optimal number of hidden neurons to produce the minimum MSE. For this application, the optimum number of hidden nodes was 3-10.

For the RBNN applications, the most difficult procedure is to find the optimal number of hidden-layer neurons and the optimal value of the spread constant that gives the minimum MSE. Thus, different numbers of hidden-layer neurons and spread constants were tried, using a trial-and-error method for each case. The optimal numbers of hidden-layer neurons and spread constants that gave the minimum MSE were found to vary between 6 and 19 and $0 \cdot 2$ and $0 \cdot 8$, respectively.

For the GRNN applications, determination of the optimal spread value for each input combination was a difficult task. Different spread values in the range $0 \cdot 01$ to 1 were examined by a trial-and-error process for each input combination to find the one that gave the minimum MSE for the given case. The optimum spreads were found to be between 0.02 and 0.09 for all cases.

For Anfis-SC applications, the most difficult procedure is to find the optimal cluster radius that gave the minimum MSE. It is important to find the proper value of the cluster radius because it shows the range of influence of a cluster. For instance, choosing a small radius will produce many small data clusters, whereas choosing a large radius will yield a few large clusters with many rules. Thus, radius values vary between 0 and 1 were tried, using a trial-and-error method for each case. The optimal values of cluster radius that gave the minimum MSE were found to vary between $0 \cdot 2$ and $0 \cdot 7$ for the cases studied.

For Anfis-GP applications, determination of the optimal number of MFs and the type of MFs is very important for the training of data. Thus, different MF types and MF numbers were examined for each input combination. For all the studied cases, a triangular MF was found to be optimal and the optimal number of MFs was found to vary between 2 and 4 .

\subsection{Comparison of FFNN, GRNN, RBNN, Anfis-SC and Anfis-GP models}

The test results of the three neural network models are shown in Table 2. It is clear from the table that the FFNN, GRNN and RBNN models gave different forecasts for different input combinations and datasets. According to the average performance of the models, input combination (I), comprising only one previous streamflow, gave the worst performance of all six input combinations for all neural networks. It is evident from Table 2 that input combinations (III), (IV), (V) and (VI) (comprising previous discharge and temperature values) performed much better than input combinations (I) and (II) (only containing previous discharge values) for all datasets. Input combination (IV) gave, on average, slightly better results than input combination (V) for the FFNN models. For the GRNN and RBNN models, input combination $(\mathrm{V})$ performed better than the other input combinations. It is evident that all three neural network models gave the worst results for dataset M1. The reason for this might be the fact that the maximum and minimum streamflows of the test dataset $\left(S_{\max }=1400 \mathrm{~m}^{3} / \mathrm{s}\right.$ and $S_{\min }=35 \cdot 3 \mathrm{~m}^{3} / \mathrm{s}$ ) were higher and lower than the extreme values of the training dataset values, respectively (see Table 1). This implies that the trained FFNN, GRNN and RBNN models faced difficulties in making extrapolations to lower and higher values in the case of dataset M1. It is clear that the FFNN, GRNN and RBNN gave good results for dataset M4 under all input combination scenarios. Table 2 clearly shows that the RBNN models performed better than the FFNN and GRNN models on the basis of average performance criteria.

Table 3 shows the test results of the best Anfis-GP and Anfis-SC models. Here again, input combinations (I) and (II) performed worse than the other input combinations. Both models gave similar results for input combinations (IV) to (VI) and showed slightly better accuracies than input combination (III) under all dataset scenarios. Similar to the FFNN, GRNN and RBNN models, Anfis-GP and Anfis-SC gave the worst results for dataset M1 due to extrapolation difficulties, as mentioned earlier. The best Anfis-GP and Anfis-SC models were obtained for dataset M4 and input combination (IV). It is clear from Table 3 that Anfis-SC performed better than Anfis-GP in one-month-ahead streamflow forecasting.

Comparing all the models (Tables 2 and 3), it is clear that the Anfis-SC model performed better than the other models in streamflow forecasting for the Gilgit river basin. The MSE values of the Anfis-SC model were smaller than those of the other models for all datasets. The $R^{2}$ values for the Anfis-SC model were higher than those of the other models for forecasting streamflow, which also indicates that the overall Anfis-SC performed better than the other four models (see Tables 2 and 3).

\subsection{Periodicity effect on streamflow forecasting}

The effect of periodicity on streamflow forecasting was investigated by adding an additional input representing the month number, which takes a value between 1 and 12 throughout the year. The test results of the periodic RBNN (P-RBNN) and periodic Anfis-SC (P-Anfis-SC) are provided in Table 4. According to the average performance of the models, P-RBNN and P-Anfis-SC showed similar accuracy for 
Table 2. Comparison of results from FFNN, GRNN and RBNN models

\begin{tabular}{|c|c|c|c|c|c|c|c|c|c|}
\hline \multirow[b]{2}{*}{ Model } & \multirow[b]{2}{*}{ Statistic } & \multirow[b]{2}{*}{ Test dataset } & \multicolumn{6}{|c|}{ Input combination } & \multirow[b]{2}{*}{ Mean } \\
\hline & & & (I) & (II) & (III) & (IV) & (V) & (VI) & \\
\hline \multirow[t]{10}{*}{ FFNN } & \multirow[t]{5}{*}{ MSE: $\times 10^{3} \mathrm{~m}^{6} / \mathrm{s}^{2}$} & M1 & $51 \cdot 78$ & $46 \cdot 67$ & $16 \cdot 99$ & $10 \cdot 99$ & $11 \cdot 52$ & $16 \cdot 78$ & $25 \cdot 79$ \\
\hline & & M2 & $48 \cdot 52$ & $16 \cdot 36$ & $7 \cdot 70$ & $6 \cdot 18$ & $5 \cdot 95$ & 6.06 & $15 \cdot 13$ \\
\hline & & M3 & $49 \cdot 36$ & $15 \cdot 99$ & $9 \cdot 20$ & $6 \cdot 95$ & $7 \cdot 20$ & $7 \cdot 95$ & $16 \cdot 11$ \\
\hline & & M4 & 45.06 & $9 \cdot 16$ & $7 \cdot 18$ & 4.93 & $5 \cdot 61$ & $5 \cdot 66$ & $12 \cdot 93$ \\
\hline & & Mean & $48 \cdot 68$ & $22 \cdot 05$ & $10 \cdot 27$ & $7 \cdot 26$ & $7 \cdot 57$ & $9 \cdot 11$ & $17 \cdot 49$ \\
\hline & \multirow[t]{5}{*}{$R^{2}$} & M1 & 0.503 & 0.578 & 0.85 & 0.909 & 0.898 & 0.841 & 0.763 \\
\hline & & M2 & 0.514 & 0.84 & 0.925 & 0.938 & 0.94 & 0.939 & 0.849 \\
\hline & & M3 & 0.519 & 0.844 & 0.912 & 0.936 & 0.931 & 0.923 & 0.844 \\
\hline & & M4 & 0.549 & 0.908 & 0.929 & 0.952 & 0.948 & 0.944 & 0.872 \\
\hline & & Mean & 0.521 & 0.793 & 0.904 & 0.934 & 0.929 & 0.912 & 0.832 \\
\hline \multirow[t]{10}{*}{ GRNN } & \multirow[t]{5}{*}{ MSE: $\times 10^{3} \mathrm{~m}^{6} / \mathrm{s}^{2}$} & M1 & $49 \cdot 95$ & $17 \cdot 73$ & $12 \cdot 28$ & $12 \cdot 10$ & $11 \cdot 39$ & 11.66 & $19 \cdot 18$ \\
\hline & & M2 & $45 \cdot 67$ & $13 \cdot 21$ & $7 \cdot 07$ & $6 \cdot 57$ & $5 \cdot 09$ & $5 \cdot 45$ & $13 \cdot 84$ \\
\hline & & M3 & $47 \cdot 68$ & $12 \cdot 57$ & $6 \cdot 44$ & $7 \cdot 10$ & $7 \cdot 34$ & 8.08 & $14 \cdot 87$ \\
\hline & & M4 & $44 \cdot 63$ & 9.98 & 4.02 & $5 \cdot 92$ & $5 \cdot 64$ & $5 \cdot 29$ & $12 \cdot 58$ \\
\hline & & Mean & $46 \cdot 98$ & $13 \cdot 37$ & $7 \cdot 45$ & $7 \cdot 92$ & $7 \cdot 36$ & $7 \cdot 62$ & $15 \cdot 12$ \\
\hline & \multirow[t]{5}{*}{$R^{2}$} & M1 & 0.524 & 0.833 & 0.885 & 0.886 & 0.893 & 0.89 & 0.819 \\
\hline & & M2 & 0.541 & 0.873 & 0.931 & 0.935 & 0.949 & 0.945 & 0.862 \\
\hline & & M3 & 0.535 & 0.878 & 0.937 & 0.936 & 0.933 & 0.924 & 0.857 \\
\hline & & M4 & 0.551 & 0.900 & 0.961 & 0.940 & 0.943 & 0.947 & 0.874 \\
\hline & & Mean & 0.538 & 0.871 & 0.929 & 0.924 & 0.930 & 0.927 & 0.853 \\
\hline \multirow[t]{10}{*}{ RBNN } & \multirow[t]{5}{*}{ MSE: $\times 10^{3} \mathrm{~m}^{6} / \mathrm{s}^{2}$} & M1 & $46 \cdot 69$ & $18 \cdot 25$ & $12 \cdot 29$ & $10 \cdot 42$ & $9 \cdot 36$ & 9.76 & $17 \cdot 79$ \\
\hline & & M2 & $45 \cdot 01$ & $10 \cdot 39$ & $7 \cdot 16$ & $6 \cdot 01$ & $6 \cdot 00$ & $5 \cdot 56$ & $13 \cdot 35$ \\
\hline & & M3 & $45 \cdot 06$ & $11 \cdot 79$ & $8 \cdot 87$ & $7 \cdot 81$ & $7 \cdot 44$ & $6 \cdot 92$ & 14.65 \\
\hline & & M4 & $42 \cdot 78$ & $9 \cdot 41$ & $7 \cdot 76$ & $5 \cdot 89$ & $5 \cdot 98$ & $9 \cdot 54$ & $13 \cdot 56$ \\
\hline & & Mean & 44.88 & $12 \cdot 46$ & 9.02 & $7 \cdot 53$ & $7 \cdot 20$ & $7 \cdot 94$ & $14 \cdot 84$ \\
\hline & \multirow[t]{5}{*}{$R^{2}$} & M1 & 0.553 & $0 \cdot 825$ & 0.886 & 0.905 & 0.916 & 0.911 & 0.833 \\
\hline & & M2 & 0.547 & 0.898 & 0.929 & 0.940 & 0.940 & 0.944 & 0.866 \\
\hline & & M3 & 0.561 & 0.886 & 0.914 & 0.926 & 0.928 & 0.934 & 0.858 \\
\hline & & M4 & 0.569 & 0.905 & 0.923 & 0.945 & 0.945 & 0.909 & 0.866 \\
\hline & & Mean & 0.558 & 0.879 & 0.913 & 0.929 & 0.932 & 0.925 & 0.856 \\
\hline
\end{tabular}

Table 3. Comparison of results from Anfis-GP and Anfis-SC models

\begin{tabular}{|c|c|c|c|c|c|c|c|c|c|}
\hline \multirow[b]{2}{*}{ Model } & \multirow[b]{2}{*}{ Statistic } & \multirow[b]{2}{*}{ Test dataset } & \multicolumn{6}{|c|}{ Input combination } & \multirow[b]{2}{*}{ Mean } \\
\hline & & & (I) & (II) & (III) & (IV) & (V) & $(\mathrm{VI})$ & \\
\hline \multirow[t]{10}{*}{ Anfis-GP } & \multirow[t]{5}{*}{ MSE: $\times 10^{3} \mathrm{~m}^{6} / \mathrm{s}^{2}$} & M1 & $47 \cdot 77$ & 23.92 & $14 \cdot 28$ & $12 \cdot 75$ & $10 \cdot 97$ & 10.99 & $20 \cdot 11$ \\
\hline & & M2 & $46 \cdot 05$ & $20 \cdot 65$ & $7 \cdot 51$ & $7 \cdot 38$ & 7.98 & 7.69 & $16 \cdot 21$ \\
\hline & & M3 & $50 \cdot 10$ & $18 \cdot 77$ & $9 \cdot 32$ & $10 \cdot 32$ & $9 \cdot 60$ & $7 \cdot 83$ & $17 \cdot 66$ \\
\hline & & M4 & $49 \cdot 13$ & $20 \cdot 41$ & $8 \cdot 29$ & $5 \cdot 37$ & $6 \cdot 36$ & $7 \cdot 03$ & $16 \cdot 10$ \\
\hline & & Mean & $48 \cdot 26$ & $20 \cdot 94$ & $9 \cdot 85$ & 8.95 & $8 \cdot 72$ & $8 \cdot 39$ & $17 \cdot 52$ \\
\hline & \multirow[t]{5}{*}{$R^{2}$} & M1 & 0.542 & 0.778 & 0.866 & 0.881 & 0.901 & 0.897 & 0.811 \\
\hline & & $\mathrm{M} 2$ & 0.536 & 0.795 & 0.926 & 0.927 & 0.922 & 0.924 & 0.838 \\
\hline & & M3 & 0.511 & 0.818 & 0.909 & 0.899 & 0.907 & 0.925 & 0.828 \\
\hline & & M4 & 0.506 & 0.794 & 0.918 & 0.95 & 0.938 & 0.935 & 0.840 \\
\hline & & Mean & 0.524 & 0.796 & 0.905 & 0.914 & 0.917 & 0.920 & 0.829 \\
\hline \multirow[t]{9}{*}{ Anfis-SC } & \multirow[t]{4}{*}{ MSE: $\times 10^{3} \mathrm{~m}^{6} / \mathrm{s}^{2}$} & M1 & $47 \cdot 26$ & $23 \cdot 10$ & $11 \cdot 61$ & $8 \cdot 41$ & $8 \cdot 14$ & 8.98 & $17 \cdot 91$ \\
\hline & & $\mathrm{M} 2$ & $47 \cdot 43$ & $19 \cdot 96$ & $6 \cdot 91$ & $5 \cdot 25$ & $5 \cdot 35$ & $5 \cdot 34$ & $15 \cdot 04$ \\
\hline & & M3 & $50 \cdot 11$ & $17 \cdot 65$ & $8 \cdot 55$ & $6 \cdot 99$ & $6 \cdot 75$ & $6 \cdot 04$ & $16 \cdot 02$ \\
\hline & & Mean & $48 \cdot 60$ & $20 \cdot 36$ & $8 \cdot 51$ & $6 \cdot 28$ & $6 \cdot 33$ & $6 \cdot 36$ & $16 \cdot 07$ \\
\hline & \multirow[t]{5}{*}{$R^{2}$} & M1 & 0.546 & 0.780 & 0.890 & 0.923 & 0.926 & 0.920 & 0.831 \\
\hline & & $\mathrm{M} 2$ & 0.523 & 0.802 & 0.934 & 0.947 & 0.946 & 0.946 & 0.850 \\
\hline & & M3 & 0.511 & 0.828 & 0.917 & 0.933 & 0.935 & 0.941 & 0.844 \\
\hline & & M4 & 0.500 & 0.791 & 0.931 & 0.961 & 0.959 & 0.951 & 0.849 \\
\hline & & Mean & 0.520 & 0.800 & 0.918 & 0.941 & 0.942 & 0.940 & 0.843 \\
\hline
\end{tabular}


Table 4. Comparison of results from P-RBNN and P-Anfis-SC models

\begin{tabular}{|c|c|c|c|c|c|c|c|c|c|}
\hline \multirow[b]{2}{*}{ Model } & \multirow[b]{2}{*}{ Statistic } & \multirow[b]{2}{*}{ Test dataset } & \multicolumn{6}{|c|}{ Input combination } & \multirow[b]{2}{*}{ Mean } \\
\hline & & & (I) & (II) & (III) & (IV) & (V) & $(\mathrm{VI})$ & \\
\hline \multirow[t]{10}{*}{ P-RBNN } & \multirow{5}{*}{ MSE: $\times 10^{3} \mathrm{~m}^{6} / \mathrm{s}^{2}$} & M1 & $13 \cdot 45$ & $12 \cdot 05$ & 11.02 & $9 \cdot 36$ & 9.71 & $9 \cdot 45$ & $10 \cdot 84$ \\
\hline & & M2 & 6.02 & $6 \cdot 70$ & $6 \cdot 15$ & $5 \cdot 25$ & $5 \cdot 81$ & $5 \cdot 16$ & 5.85 \\
\hline & & M3 & $8 \cdot 32$ & 9.53 & $8 \cdot 12$ & $7 \cdot 81$ & $6 \cdot 97$ & $6 \cdot 85$ & 7.93 \\
\hline & & M4 & $5 \cdot 65$ & $7 \cdot 14$ & 6.85 & $5 \cdot 10$ & 5.79 & $5 \cdot 47$ & $6 \cdot 00$ \\
\hline & & Mean & $8 \cdot 36$ & 8.86 & 8.04 & $6 \cdot 88$ & $7 \cdot 07$ & $6 \cdot 73$ & $7 \cdot 65$ \\
\hline & \multirow[t]{5}{*}{$R^{2}$} & M1 & 0.872 & 0.886 & 0.898 & 0.917 & 0.914 & 0.912 & 0.900 \\
\hline & & M2 & 0.939 & 0.933 & 0.942 & 0.949 & 0.942 & 0.948 & 0.942 \\
\hline & & M3 & 0.92 & 0.911 & 0.921 & 0.926 & 0.933 & 0.935 & 0.924 \\
\hline & & M4 & 0.944 & 0.928 & 0.932 & 0.95 & 0.944 & 0.949 & 0.941 \\
\hline & & Mean & 0.919 & 0.915 & 0.923 & 0.936 & 0.933 & 0.936 & 0.927 \\
\hline \multirow[t]{10}{*}{ P-Anfis-SC } & \multirow[t]{5}{*}{ MSE: $\times 10^{3} \mathrm{~m}^{6} / \mathrm{s}^{2}$} & M1 & $13 \cdot 78$ & $12 \cdot 44$ & 13.90 & $8 \cdot 16$ & $8 \cdot 22$ & $8 \cdot 61$ & $10 \cdot 85$ \\
\hline & & $\mathrm{M} 2$ & $5 \cdot 900$ & $6 \cdot 25$ & $5 \cdot 25$ & $4 \cdot 81$ & $4 \cdot 61$ & $4 \cdot 31$ & $5 \cdot 19$ \\
\hline & & M3 & 8.59 & 9.80 & $7 \cdot 69$ & $7 \cdot 37$ & $6 \cdot 71$ & $7 \cdot 00$ & 7.86 \\
\hline & & M4 & $5 \cdot 45$ & 6.05 & $6 \cdot 24$ & $4 \cdot 22$ & 4.59 & $5 \cdot 72$ & $5 \cdot 38$ \\
\hline & & Mean & 8.44 & 8.63 & 8.27 & $6 \cdot 14$ & 6.04 & $6 \cdot 41$ & $7 \cdot 32$ \\
\hline & \multirow[t]{5}{*}{$R^{2}$} & M1 & 0.872 & 0.883 & 0.874 & 0.926 & 0.93 & 0.923 & 0.901 \\
\hline & & $\mathrm{M} 2$ & 0.941 & 0.937 & 0.948 & 0.952 & 0.954 & 0.957 & 0.948 \\
\hline & & M3 & 0.917 & 0.907 & 0.926 & 0.929 & 0.935 & 0.932 & 0.924 \\
\hline & & M4 & 0.946 & 0.940 & 0.938 & 0.96 & 0.957 & 0.952 & 0.949 \\
\hline & & Mean & 0.919 & 0.917 & 0.922 & 0.942 & 0.944 & 0.941 & 0.931 \\
\hline
\end{tabular}

Table 5. Comparison of results from Sarima models

$\begin{array}{llrrr}\text { Cross-validation } & \text { Model } & \text { Test dataset } & \text { MSE: } \times \mathbf{1 0}^{\mathbf{3}} \mathbf{m}^{\mathbf{6}} \mathbf{s}^{\mathbf{2}} & \boldsymbol{R}^{\mathbf{2}} \\ \text { M1 } & \text { Arima }(1,0,1)(2,1,0)_{12} & 1999-2010 & 17 \cdot 23 & 0 \cdot 849 \\ \text { M2 } & \text { Arima }(1,0,1)(2,1,1)_{12} & 1987-1998 & 9 \cdot 23 & 0.909 \\ \text { M3 } & \text { Arima }(1,0,2)(0,1,1)_{12} & 1975-1986 & 10 \cdot 94 & 0.897 \\ \text { M4 } & \text { Arima }(1,0,1)(0,1,2)_{12} & 1963-1974 & 7 \cdot 46 & 0.926 \\ \text { Mean } & & & 11 \cdot 22 & 0.895\end{array}$

different input combinations. Again, both models performed the worst for dataset M1 but performed very well for dataset M4. In both models, input combinations (IV) to (VI) led to slightly better performance than input combinations (I) to (III). By adding the periodicity component, the average MSE of the RBNN and Anfis-SC models was increased by 47.2 and $54.4 \%$, respectively. However, P-Anfis-SC was determined to be the best model for forecasting one-month-ahead streamflow forecasting because it had the least MSE and the highest $R^{2}$ under all input combination scenarios for all datasets.

Different Sarima models were also tested to examine the periodicity effect by using the same datasets. The results of the best Sarima models are shown in Table 5. It is evident from the table that the Sarima models also produced the worst results for dataset M1, similar to the previous applications, while dataset M4 produced good results for the Sarima models. Comparison of Tables 4 and 5 shows that the P-RBNN and P-Anfis-SC performed much better than the Sarima models for all the datasets. Compared with the Sarima models, the average MSE accuracy was increased by $25 \cdot 5$ and $24.7 \%$ for the P-RBNN and P-Anfis-SC applications, respectively.
Figure 8 shows the observed monthly streamflows and the streamflows forecasted by the P-RBNN, P-Anfis-SC and Sarima models for datasets M1-M4. With higher values of $R^{2}$ for each dataset, the plots show that the P-RBNN and P-Anfis-SC models provided a better fit to the observed streamflow data in comparison to the Sarima models. However, the P-Anfis-SC model seems to be better than the P-RBNN and Sarima models with respect to the line-fit equations $\left(y=a_{0} x+a_{1}\right)$ and $R^{2}$ coefficients in Figures 8(a)-8(d) as the coefficients $a_{0}$ and $a_{1}$ for the P-Anfis-SC model were respectively closer to 1 and 0 than those of the P-RBNN and Sarima models.

\section{Conclusions}

In this study, monthly streamflow data of the Gilgit river basin were used to examine the forecasting capability of FFNN, GRNN, RBNN, Anfis-GP, Anfis-SC and Sarima models. Two statistical parameters, MSE and $R^{2}$, were used to evaluate the performance of these models. In the first part of the study, five soft computing methods were applied in one-month-ahead streamflow prediction by using different antecedent streamflow and temperature inputs. To better evaluate the prediction capability, cross-validation was also applied in all cases. A comparison of the results showed that the RBNN and 

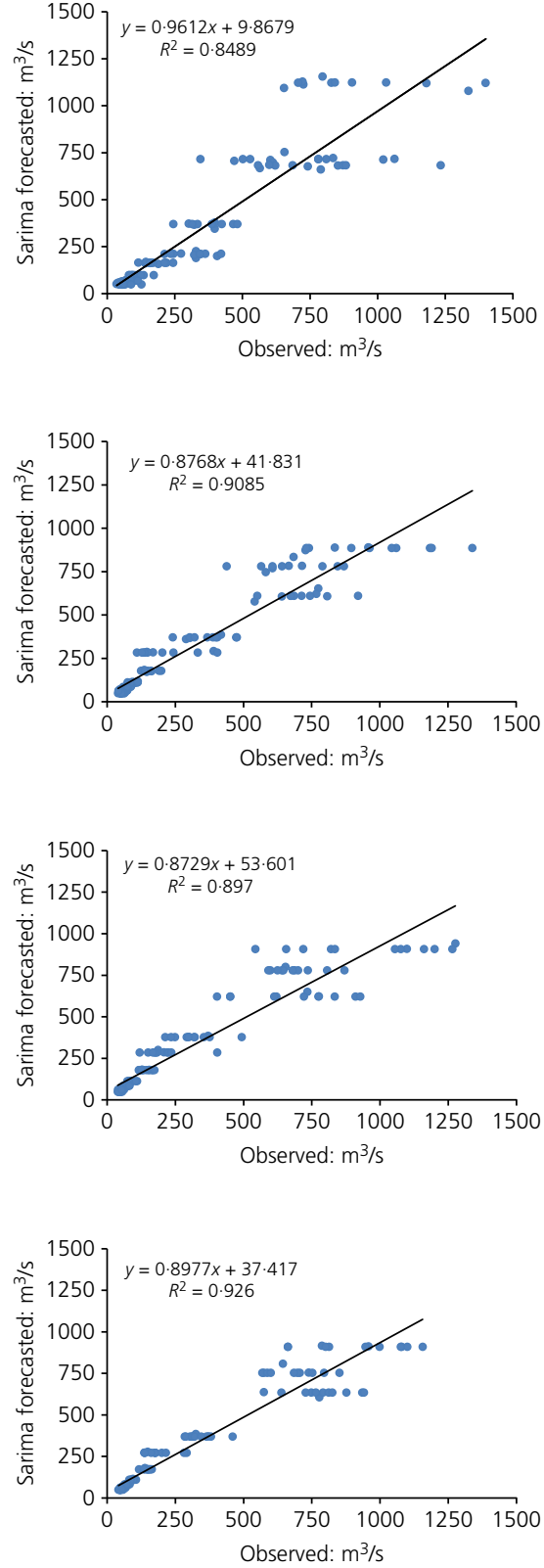

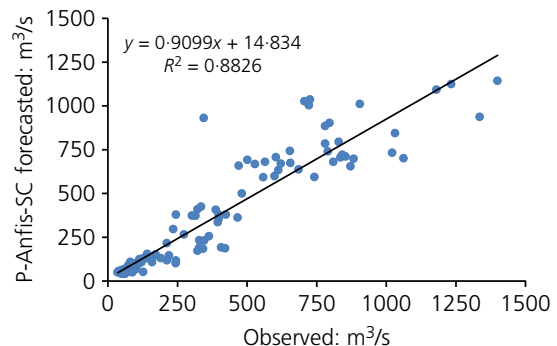

(a)

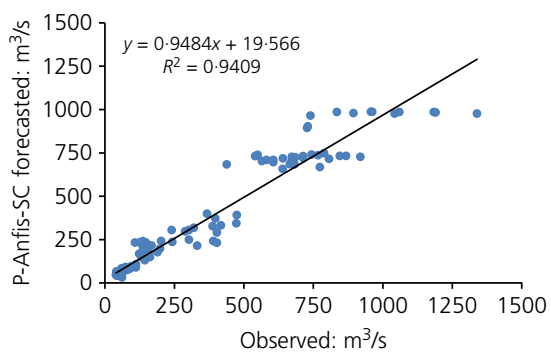

(b)

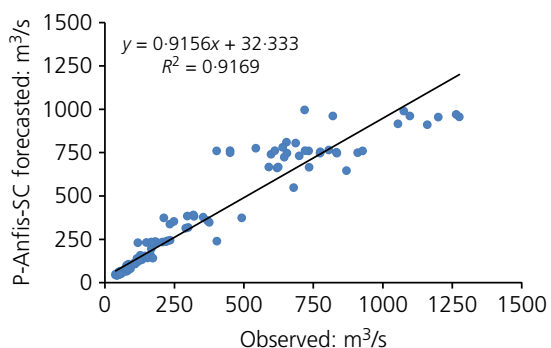

(c)

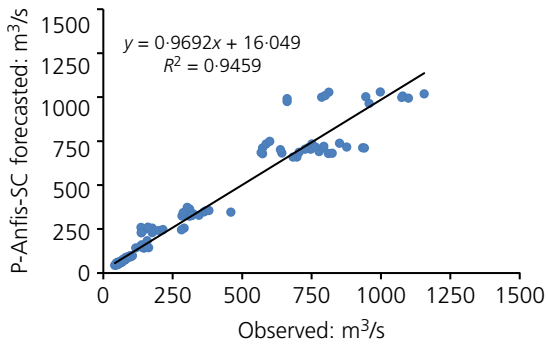

(d)
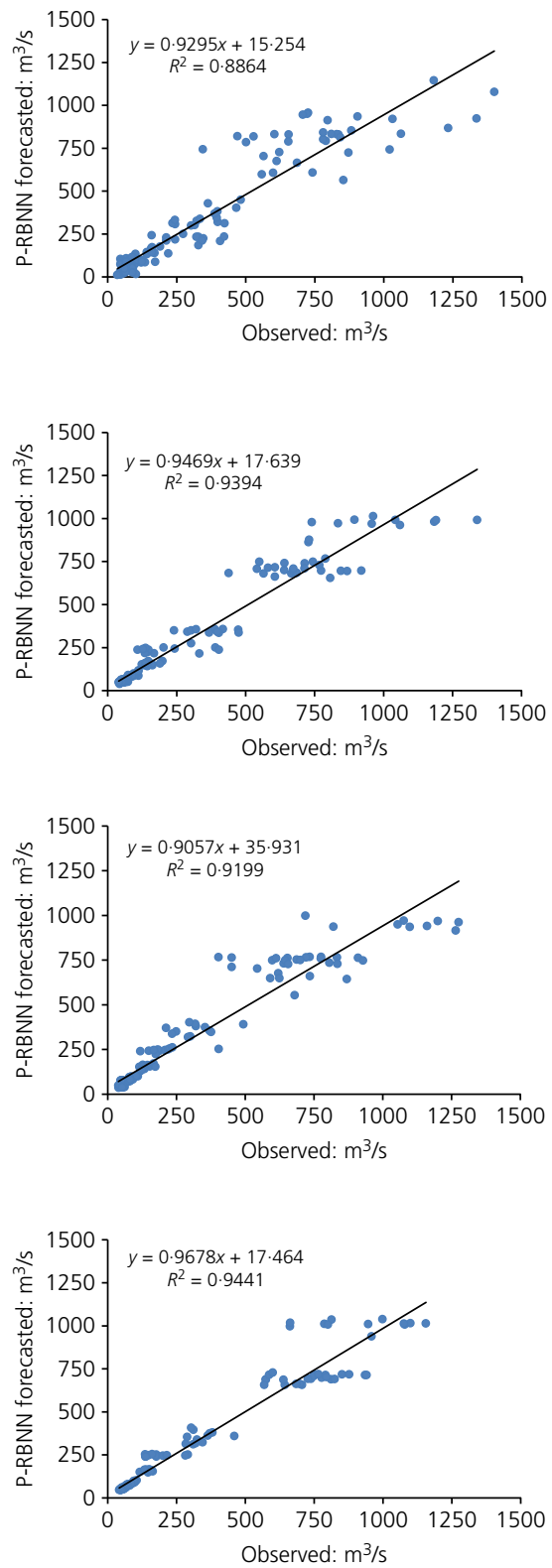

Figure 8. Observed and forecasted streamflows by Sarima, P-Anfis-SC and P-RBNN for dataset (a) M1, (b) M2, (c) M3 and (d) M4

Anfis-SC models performed better than the other soft computing models, and dataset M1 gave the worst results for all models due to extrapolation difficulties. In the second part of the study, the effect of periodicity was examined using RBNN and Anfis-SC models. The results of these two models after adding periodicity (P-RBNN and P-Anfis-SC) were compared with results from the Sarima model. P-RBNN and P-Anfis-SC performed better than Sarima for each dataset and, moreover, gave better results than the original models without periodicity. Inputting periodicity thus increased the prediction accuracy of these models. Compared with the P-RBNN and P-Anfis-SC applications, the average MSE of Sarima was increased by $25 \cdot 5-24 \cdot 7 \%$, whereas the average MSEs of the RBNN and Anfis-SC models were increased by $47 \cdot 2-54 \cdot 4 \%$. The overall results showed that the P-Anfis-SC performed better than the P-RBNN model.

The necessity and effect of considering the interaction between temperature and streamflow in streamflow forecasting has been proved in this study. This finding could help water resource planners and managers achieve accurate prediction results. 


\section{Acknowledgements}

This work was supported by the National Natural Science Foundation of China (no. 51379080 and no. 41571514) and Fundamental Research Funds for the Central Universities (no. 2017KFYXJJ204).

\section{REFERENCES}

Abonyi J, Andersen H, Nagy L and Szeifert F (1999) Inverse fuzzyprocess-model based direct adaptive control. Mathematics and Computers in Simulation 51(1): 119-132.

Azmathullah HM, Deo M and Deolalikar P (2005) Neural networks for estimation of scour downstream of a ski-jump bucket. Journal of Hydraulic Engineering 131(10): 898-908.

Bartholomew DJ (1971) Time series analysis forecasting and control. Journal of the Operational Research Society 22(2): 199-201

Chen ZH, Yuan XH, Ji B, Wang PT and Tian H (2014) Design of a fractional order PID controller for hydraulic turbine regulating system using chaotic non-dominated sorting genetic algorithm II. Energy Conversion and Management 84: 390-404, https://doi.org/ 10.1016/j.enconman.2014.04.052.

Chiu SL (1994) Fuzzy model identification based on cluster estimation. Journal of Intelligent \& Fuzzy Systems 2(3): 267-278.

Chu HJ and Chang LC (2009) Application of optimal control and fuzzy theory for dynamic groundwater remediation design. Water Resources Management 23(4): 647-660.

Cigizoglu HK and Kisi O (2005) Flow prediction by three back propagation techniques using $\mathrm{k}$-fold partitioning of neural network training data. Hydrology Research 36(1): 49-64.

Cobaner M (2011) Evapotranspiration estimation by two different neuro-fuzzy inference systems. Journal of Hydrology 398(3): 292-302.

El-Shafie A, Taha MR and Noureldin A (2007) A neuro-fuzzy model for inflow forecasting of the Nile river at Aswan high dam. Water Resources Management 21(3): 533-556.

Emamgholizadeh S, Kashi H, Marofpoor I and Zalaghi E (2014) Prediction of water quality parameters of Karoon River (Iran) by artificial intelligence-based models. International Journal of Environmental Science and Technology 11(3): 645-656

Greco R (2012) A fuzzy-autoregressive model of daily river flows. Computers \& Geosciences 43(6): 17-23.

Hu TS, Lam KC and Ng ST (2005) A modified neural network for improving river flow prediction. Hydrological Sciences Journal 50(2): 299-318.

Kagoda PA, Ndiritu J, Ntuli C and Mwaka B (2010) Application of radial basis function neural networks to short-term streamflow forecasting. Physics and Chemistry of the Earth Parts $\mathrm{A} / \mathrm{B} / \mathrm{C}$ 35(13): 571-581.

Kisi O (2007) Streamflow forecasting using different artificial neural network algorithms. Journal of Hydrologic Engineering 12(5): $532-539$.

Kisi O (2015) Streamflow forecasting and estimation using least square support vector regression and adaptive neuro-fuzzy embedded fuzzy c-means clustering. Water Resources Management 29(14) 5109-5127.

Maier HR and Dandy GC (2000) Neural networks for the prediction and forecasting of water resources variables: a review of modelling issues and applications. Environmental Modelling \& Software 15(1): $101-124$

Mehr AD, Kahya E, Sahin A and Nazemosadat MJ (2015) Successive-station monthly streamflow prediction using different artificial neural network algorithms. International Journal of Environmental Science and Technology 12(7): 2191-2200.
Modarres R and Ouarda T (2013) Modelling heteroscedasticty of streamflow times series. Hydrological Sciences Journal 58(1): 54-64.

Mutlu E, Chaubey I, Hexmoor H and Bajwa SG (2008) Comparison of artificial neural network models for hydrologic predictions at multiple gauging stations in an agricultural watershed. Hydrological Processes 22(26): 5097-5106.

Nourani V, Baghanam AH, Adamowski J and Gebremichael M (2013) Using self-organizing maps and wavelet transforms for space-time pre-processing of satellite precipitation and runoff data in neural network based rainfall-runoff modeling. Journal of Hydrology 476(1): 228-243

Pramanik N and Panda RK (2009) Application of neural network and adaptive neuro-fuzzy inference systems for river flow prediction. Hydrological Sciences Journal 54(2): 247-260.

Sanikhani H and Kisi O (2012) River flow estimation and forecasting by using two different adaptive neuro-fuzzy approaches. Water Resources Management 26(6): 1715-1729.

Sharma S, Srivastava P, Fang X and Kalin L (2015) Performance comparison of adoptive neuro fuzzy inference system (Anfis) with loading simulation program $\mathrm{C}++(\mathrm{LSPC})$ model for streamflow simulation in El Nino southern oscillation (ENSO)-affected watershed. Expert Systems with Applications 42(4): 2213-2223.

Specht DF (1991) A general regression neural network. IEEE Transactions on Neural Networks 2(6): 568-576.

Tahershamsi A, Tabatabai MM and Shirkhani R (2012) An evaluation model of artificial neural network to predict stable width in gravel bed rivers. International Journal of Environmental Science and Technology 9(2): 333-342.

Takagi T and Sugeno M (1985) Fuzzy identification of systems and its applications to modeling and control. IEEE Transactions on Systems, Man and Cybernetics 15(1): 116-132.

Talebizadeh M and Moridnejad A (2011) Uncertainty analysis for the forecast of lake level fluctuations using ensembles of Ann and Anfis models. Expert Systems with Applications 38(4): 4126-4135.

Talei A, Chua LH and Wong TS (2010) Evaluation of rainfall and discharge inputs used by adaptive network-based fuzzy inference systems (Anfis) in rainfall-runoff modeling. Journal of Hydrology 391(3): 248-262.

Valipour M (2015) Long-term runoff study using Sarima and Arima models in the United States. Meteorological Applications 22(3) 592-598.

Yager RR and Filev DP (1994) Approximate clustering via the mountain method. IEEE Transactions on Systems, Man and Cybernetics 24(8): 1279-1284

\section{How can you contribute?}

To discuss this paper, please email up to 500 words to the editor at journals@ice.org.uk. Your contribution will be forwarded to the author(s) for a reply and, if considered appropriate by the editorial board, it will be published as discussion in a future issue of the journal.

Proceedings journals rely entirely on contributions from the civil engineering profession (and allied disciplines). Information about how to submit your paper online is available at www.icevirtuallibrary.com/page/authors, where you will also find detailed author guidelines 